\title{
Assessing the complex sponge microbiota: core, variable and species-specific bacterial communities in marine sponges
}

\author{
Susanne Schmitt ${ }^{1,2,12}$, Peter Tsai ${ }^{3}$, James Bell ${ }^{4}$, Jane Fromont ${ }^{5}$, Micha Ilan ${ }^{6}$, \\ Niels Lindquist ${ }^{7}$, Thierry Perez ${ }^{8}$, Allen Rodrigo ${ }^{3,9}$, Peter J Schupp ${ }^{10,13}$, Jean Vacelet $^{8}$, \\ Nicole Webster ${ }^{11}$, Ute Hentschel ${ }^{2}$ and Michael W Taylor ${ }^{1}$ \\ ${ }^{1}$ Centre for Microbial Innovation, School of Biological Sciences, University of Auckland, Private Bag 92019, \\ Auckland, New Zealand; ${ }^{2} J u l i u s-v o n-S a c h s ~ I n s t i t u t e$ for Biological Sciences, University of Wuerzburg, \\ Julius-von-Sachs Platz 3, Wuerzburg, Germany; ${ }^{3}$ Bioinformatics Institute, University of Auckland, Private Bag \\ 92019, Auckland, New Zealand; ${ }^{4}$ Centre for Marine Environmental and Economic Research, School of \\ Biological Sciences, Victoria University of Wellington, Kelburn Pde, Kelburn Campus, Wellington, \\ New Zealand; ${ }^{5}$ Western Australian Museum, Locked Bag 49, Welshpool DC, Western Australia, Australia; \\ ${ }^{6}$ Department of Zoology, Tel Aviv University, Tel Aviv, Israel; ${ }^{7}$ Institute of Marine Sciences, University \\ of North Carolina at Chapel Hill, 3431 Arendell Street, Morehead City, NC, USA; ${ }^{8}$ Centre d'Océanologie \\ de Marseille, Aix-Marseille Université, CNRS UMR 6540 DIMAR, Station Marine d'Endoume Rue \\ Batterie-des-Lions Marseille 13007, France; ${ }^{9}$ Biology Department, Duke University, Durham, NC, USA; \\ ${ }^{10}$ Marine Laboratory, University of Guam, Mangilao, GU, USA and ${ }^{11}$ Australian Institute of Marine Sciences, \\ PMB 3, Townsville Mail Center, Queensland, Australia
}

\begin{abstract}
Marine sponges are well known for their associations with highly diverse, yet very specific and often highly similar microbiota. The aim of this study was to identify potential bacterial sub-populations in relation to sponge phylogeny and sampling sites and to define the core bacterial community. 16S ribosomal RNA gene amplicon pyrosequencing was applied to 32 sponge species from eight locations around the world's oceans, thereby generating 2567 operational taxonomic units (OTUs at the $97 \%$ sequence similarity level) in total and up to 364 different OTUs per sponge species. The taxonomic richness detected in this study comprised 25 bacterial phyla with Proteobacteria, Chloroflexi and Poribacteria being most diverse in sponges. Among these phyla were nine candidate phyla, six of them found for the first time in sponges. Similarity comparison of bacterial communities revealed no correlation with host phylogeny but a tropical sub-population in that tropical sponges have more similar bacterial communities to each other than to subtropical sponges. A minimal core bacterial community consisting of very few OTUs (97\%, $95 \%$ and $90 \%$ ) was found. These microbes have a global distribution and are probably acquired via environmental transmission. In contrast, a large species-specific bacterial community was detected, which is represented by OTUs present in only a single sponge species. The species-specific bacterial community is probably mainly vertically transmitted. It is proposed that different sponges contain different bacterial species, however, these bacteria are still closely related to each other explaining the observed similarity of bacterial communities in sponges in this and previous studies. This global analysis represents the most comprehensive study of bacterial symbionts in sponges to date and provides novel insights into the complex structure of these unique associations.
\end{abstract}

The ISME Journal (2012) 6, 564-576; doi:10.1038/ismej.2011.116; published online 13 October 2011

Subject Category: microbe-microbe and microbe-host interactions

Keywords: biogeography; candidate phyla; core microbiota; bacterial diversity; marine sponges; 454-pyrosequencing

Correspondence: S Schmitt, Department of Earth and Environmental Sciences, Paleontology and Geobiology, Ludwig-MaximilansUniversität in Munich, Richard Wagner Str. 10, 80333 Munich, Germany.

E-mail: s.schmitt@lrz.uni-muenchen.de

${ }^{12}$ Current address: Department of Earth and Environmental Sciences, Paleontology and Geobiology, Ludwig-Maximilians-University in Munich, Richard-Wagner-Street 10, 80333 Munich, Germany.

${ }^{13}$ Current address: Institute for Chemistry and Biology of the Marine Environment, Postfach 2503, University of Oldenburg, 26111 Oldenburg, Germany.

Received 1 December 2010; revised 15 July 2011; accepted 28 July 2011; published online 13 October 2011 


\section{Introduction}

The recent advent of massively parallel sequencing technologies has revolutionized microbial diversity and ecology studies. Deep sequencing of $16 \mathrm{~S}$ ribosomal RNA (rRNA) gene amplicon libraries showed that microbial communities in many environments including marine habitats, soil, plants and humans, are much more diverse than previously thought (Huber et al., 2007; Costello et al., 2009; Turnbaugh et al., 2009; Andersson et al., 2010; Hollister et al., 2010; Teixeira et al., 2010). Many of these newly detected microbes represent the rare biosphere (Sogin et al., 2006). They are not abundant but collectively represent most of the diversity within a sample. A recent 454 pyrosequencing study showed that marine sponges host bacterial communities with a diversity that is unparalleled in any invertebrate host (Webster et al., 2010).

Sponges are the oldest and most primitive of the metazoan phyla with a global distribution in essentially all aquatic habitats. They are ecologically important and a rich source of novel, biotechnologically relevant natural products. The association of some species with dense and complex microbial consortia has long been recognized (Vacelet 1975; Vacelet and Donadey 1977; Wilkinson et al., 1981) and these sponges were termed bacteriosponges or 'high microbial abundance' sponges to distinguish them from co-occurring sponges in the same habitat that lack dense microbial communities (which were thus termed 'low microbial abundance' sponges) (Reiswig 1981; Hentschel et al., 2003). In high microbial abundance sponges, microbes can comprise as much as $40 \%$ of the sponge biomass and represent a variety of different morphotypes (Vacelet 1975). Phylogenetic studies identified members of 26 different bacterial phyla (Taylor et al., 2007; Webster et al., 2008, 2010; Sipkema et al., 2009) including the candidate phylum 'Poribacteria' that is almost exclusively found within sponges (Fieseler et al., 2004; Lafi et al., 2009). Sponge symbionts are capable of diverse metabolic processes such as nitrification, nitrogen fixation, sulfate reduction and photosynthesis (Wilkinson 1979; Hoffmann et al., 2006, 2009; Bayer et al., 2008; Mohamed et al., 2010) and probably contribute to sponge nutrition (Weisz et al., 2007). Additionally, certain sponge symbionts produce secondary metabolites that might be involved in the chemical defense of their hosts (Kennedy et al., 2007; Siegl and Hentschel 2010; Thomas et al., 2010a). Genomic information is currently being used to further characterize features of symbiosis and physiological properties and the lifestyle of sponge symbionts (Hochmuth et al., 2010; Thomas et al., 2010b; Siegl et al., 2011).

A recurring phenomenon in sponge microbiology is the high similarity among sponge-associated bacterial communities. This was first described by Hentschel et al., (2002) who showed that sponge-derived $16 \mathrm{~S}$ rRNA gene sequences cluster together regardless of their origin (host sponge and/or sampling location). The term 'sponge-specific' was introduced for these clusters to describe a phylogenetically complex community that is repeatedly detected in sponges around the world but that is different from microbial seawater communities (Hentschel et al., 2002; Taylor et al., 2007). Interestingly, sponge-specific microbes are mainly found in high microbial abundance sponges whereas low microbial abundance sponges usually have a much lower microbial diversity and a different microbial profile (Hentschel et al., 2006; Kamke et al., 2010). Given the observed uniformity of spongespecific communities, the aim of this study was to identify geographical or host-dependent bacterial subpopulations in sponges and to define the bacterial core community that is shared among most sponges as well as the species-specific community that is unique to a certain sponge species.

\section{Materials and methods}

Sponge collection, sample preparation and 454 pyrosequencing

Tissue samples from three individuals of each of 31 sponge species and from a single individual of an unidentified sponge S1 (Table 1) were collected at eight different locations in the Indian and Pacific Ocean, the Caribbean, Mediterranean and Red Sea at depths between 1.5 and $18 \mathrm{~m}$ while SCUBA diving (for sampling details see Supplementary Table S1). All samples were frozen at $-80^{\circ} \mathrm{C}$ for at least $24 \mathrm{~h}$, then freeze-dried for another $24 \mathrm{~h}$ and kept at $-20^{\circ} \mathrm{C}$ until further processing. DNA was extracted using a hexadecyltrimethylammonium bromide (CTAB)based protocol (Taylor et al., 2004) from each individual of all sponges except sponge S1 where three different tissue samples of one individual were used. Briefly, cells were disrupted by bead-beating in an ammonium acetate extraction buffer containing chloroform:isoamyl alcohol (24:1). DNA was precipitated with $3 \mathrm{M}$ sodium acetate and isopropanol, then washed in $70 \%$ ethanol, dried and redissolved in $\mathrm{H}_{2} \mathrm{O}_{\text {dd }}$. Purity and quantity of DNA was determined with a Nanodrop 1000 spectrophotometer (Thermo Scientific, Wilmington, DE, USA) and only high quality DNA was used for subsequent PCR reactions. PCRs were performed using the FastStart high fidelity PCR system (Roche Diagnostics N.Z. Ltd, Auckland, New Zealand) and the modified primer pair 338f and 533r $\left(338 f_{\text {deg }}\right.$ : $5^{\prime}$-ACW CCT ACG GGW GGC WGC AG-3' ${ }^{\prime}$ 533r $\mathrm{r}_{\mathrm{deg}}$ : $5^{\prime}$-TKA CCG CRG CTG CTG GCA C-3') to amplify a ca 145-bp fragment of the 16S rRNA gene including the hypervariable V3 region. The degenerate primers $338 f_{\text {deg }}$ and $533 r_{\text {deg }}$ were complemented with adaptors $\mathrm{A}$ and $\mathrm{B}$, respectively, as recommended by Roche, and the forward primer contained one of the three multiplex identifier barcodes CATG, CGAT or CTGA. For the downstream pyrosequencing step, two samples were combined for sequencing per plate region (that is, 32 samples on 16 regions) hence two different multiplex identifiers were used per plate 
Table 1 Sponge samples and sequence data summary

\begin{tabular}{|c|c|c|c|c|c|c|}
\hline $\begin{array}{l}\text { Sampling } \\
\text { location }\end{array}$ & $\begin{array}{l}\text { Sponge } \\
\text { sample }\end{array}$ & $\begin{array}{l}\text { Sponge } \\
\text { order }\end{array}$ & $\begin{array}{c}\text { Seqs after } \\
R^{\mathrm{a}}\end{array}$ & $\begin{array}{c}\text { Seqs after } \\
\text { LUCY }^{\mathrm{b}}\end{array}$ & $\begin{array}{c}\text { No. of } \\
\text { unique seqs }\end{array}$ & $\begin{array}{c}\text { No. of } \\
97 \% \text { OTUs }\end{array}$ \\
\hline \multirow[t]{4}{*}{ ANZ } & Ancorina alata & Astrophorida & 3730 & 3327 & 736 & 352 \\
\hline & Polymastia sp. & Hadromerida & 1294 & 1276 & 127 & 45 \\
\hline & sponge $\mathrm{S} 1$ & unidentified & 1063 & 990 & 293 & 163 \\
\hline & Stelletta maori & Astrophorida & 1850 & 1533 & 459 & 227 \\
\hline \multirow[t]{4}{*}{ CAR } & Aplysina archeri & Verongida & 790 & 746 & 245 & 159 \\
\hline & Ircinia felix & Dictyoceratida & 1359 & 1269 & 323 & 179 \\
\hline & Pseudoceratina crassa & Verongida & 820 & 743 & 280 & 176 \\
\hline & Xestospongia muta & Haplosclerida & 1509 & 1395 & 440 & 243 \\
\hline \multirow[t]{4}{*}{ GBR } & Cymbastela coralliophila & Halichondrida & 282 & 259 & 71 & 38 \\
\hline & Hyrtios sp. & Dictyoceratida & 1429 & 1347 & 304 & 162 \\
\hline & Ircinia gigantea & Dictyoceratida & 377 & 365 & 108 & 86 \\
\hline & Xestospongia testudinaria & Haplosclerida & 3166 & 2751 & 679 & 364 \\
\hline \multirow[t]{5}{*}{ GUAM } & Hyrtios altum & Dictyoceratida & 2164 & 2056 & 295 & 157 \\
\hline & Pseudoceratina sp. & Verongida & 618 & 575 & 209 & 141 \\
\hline & Rhabdastrella globostellata & Astrophorida & 1925 & 1779 & 490 & 286 \\
\hline & Stylissa massa & Halichondrida & 86 & 78 & 37 & 25 \\
\hline & Xestospongia aff. carbonaria & Haplosclerida & 201 & 162 & 78 & 36 \\
\hline \multirow[t]{3}{*}{ IND } & Chondrilla australiensis & Chondrosida & 106 & 96 & 60 & 42 \\
\hline & Hippospongia sp. & Dictyoceratida & 1753 & 1635 & 377 & 188 \\
\hline & Ircinia sp. & Dictyoceratida & 1211 & 1179 & 319 & 159 \\
\hline \multirow[t]{5}{*}{ MED } & Aplysina aerophoba & Verongida & 868 & 831 & 229 & 133 \\
\hline & Aplysina cavernicola & Verongida & 1006 & 908 & 188 & 119 \\
\hline & Ircinia variabilis & Dictyoceratida & 741 & 709 & 178 & 111 \\
\hline & Petrosia ficiformis & Haplosclerida & 660 & 595 & 225 & 142 \\
\hline & Pseudocorticium jarrei & Homosclerophorida & 269 & 255 & 60 & 44 \\
\hline \multirow[t]{3}{*}{ RS } & Biemna ehrenbergi & Poecilosclerida & 704 & 648 & 176 & 111 \\
\hline & Hyrtios erectus & Dictyoceratida & 806 & 756 & 198 & 124 \\
\hline & Theonella swinhoei & Lithistida & 429 & 373 & 189 & 131 \\
\hline \multirow[t]{4}{*}{ WNZ } & Ancorina sp. & Astrophorida & 787 & 748 & 308 & 190 \\
\hline & Plakina trilopha & Homosclerophorida & 856 & 823 & 224 & 109 \\
\hline & Stelletta aremaria & Astrophorida & 1916 & 1852 & 440 & 250 \\
\hline & Xestospongia sp. & Haplosclerida & 166 & 149 & 64 & 55 \\
\hline
\end{tabular}

Abbreviations: ANZ, Auckland, New Zealand; CAR, Caribbean Sea; GBR, Great Barrier Reef; GUAM, Guam, Pacific Ocean; IND, Indian Ocean; MED, Mediterranean Sea; OTU, operational taxonomic unit; RDP, Ribosomal Database Project; RS, Red Sea; WNZ, Wellington, New Zealand. ${ }^{a}$ No. of tag sequences after initial quality control using the pyrosequencing pipeline in the Ribosomal Database Project (RDP).

${ }^{\mathrm{b}}$ No. of tag sequences after end-trimming using the software LUCY.

region. PCR conditions were as follows: initial denaturing step at $94{ }^{\circ} \mathrm{C}$ for $3 \mathrm{~min}, 30$ cycles of denaturing at $94{ }^{\circ} \mathrm{C}$ for $30 \mathrm{~s}$, primer annealing at $57^{\circ} \mathrm{C}$ for $45 \mathrm{~s}$ and extension at $72^{\circ} \mathrm{C}$ for $20 \mathrm{~s}$, followed by a final extension step at $72^{\circ} \mathrm{C}$ for $5 \mathrm{~min}$. Product quantity was assessed using a Nanodrop 1000 spectrophotometer and product purity was determined with Agilent 1200 Bioanalyzer DNA 1000 chips (Agilent technologies, Santa Clara, CA, USA). Finally, equal amounts of PCR products were pooled from all three individuals per species and the three tissue parts of sponge S1. Amplicon libraries were sequenced with a 454 Life Sciences FLX pyrosequencer (University of Otago, Dunedin, New Zealand). Pyrotag sequence data were deposited in the National Center for Biotechnology Information Sequence Read Archive under accession number SRP003545.

Tag sequence analyses

The Ribosomal Database Project pyrosequencing pipeline (http://pyro.cme.msu.edu/) was used to sort tag sequences according to the multiplex identifiers and to remove low quality sequences (all sequences with ambiguous nucleotides and/or without an identical forward primer and/or a length shorter than $125 \mathrm{bp}$ ). To avoid overestimating the true diversity because of erroneous tag reads as a result of sequencing errors and formation of homopolymers and chimeras (Reeder and Knight 2009), we followed the approach of Kunin et al. (2010) who used quality score-based filtering and a low operational taxonomic unit (OTU) threshold clustering. Our tag sequences were end-trimmed based on quality scores at a stringency of $0.2 \%$ per base error probability using LUCY (Chou and Holmes 2001). Unique sequences were identified with Mothur 1.9.0 (Schloss et al., 2009), aligned against a SILVA alignment (available at http://www.mothur.org/wiki/ Alignment_database) using a kmer search and a Needleman algorithm, and then grouped into $90 \%$, $95 \%$ and $97 \%$ OTUs based on uncorrected pairwise distance matrices (furthest neighbor algorithm). The last steps were performed separately for all tag 
sequences from each sponge species, for all tag sequences from each of the eight locations, and for all tag sequences combined. A representative sequence (defined as implemented in Mothur) of each OTU was used for the taxonomic assignment using customized perl scripts similar to the approach used by Sogin et al., (2006) and Webster et al., (2010). For each tag sequence, a BLAST search (Altschul et al., 1990) was performed against a manually modified SILVA version 98 database. Pairwise global alignments were performed between each of the 10 best hits against the tag sequence using a Smith-Waterman algorithm. The most similar sequence to the tag sequence (or multiple sequences if within a range of $0.1 \%$ sequence divergence) was then used for assignment according to the Ribosomal Database Project taxonomy implemented in the SILVA database. For assignment at phylum, class, order, family and genus level, sequence similarity thresholds of $75 \%, 80 \%, 85 \%, 90 \%$ and $95 \%$ were applied, following Webster et al., (2010). In cases where the taxonomy of the most similar sequences was inconsistent, a majority rule was applied and the tag was only assigned if at least $60 \%$ of all reference sequences shared the same taxonomic annotation at the respective taxonomic level. All previously published, sponge-derived sequences in the SILVA reference database were labeled as such and it was noted when a tag sequence was assigned to a sponge-derived sequence. On the basis of the taxonomic assignment, Bray-Curtis similarities were calculated using the program PRIMER 6 (Primer-E Ltd, Plymouth, UK) and visualized as heatmaps using JColorGrid (Joachimiak et al., 2006). Bray-Curtis similarities were also used for unweighted pair-group average cluster analyses with Primer-6.

\section{Results and Discussion}

Taxonomic richness of the sponge microbiota

Overall, 2567 different 97\% OTUs were obtained from the 32 sponges and up to 364 different $97 \%$ OTUs from a single sponge species (Table 1). At phylum level, all 97\% OTUs could be classified and belonged to 16 formally described bacterial phyla, 9 candidate phyla and 1 unclassified lineage (sponge-associated unclassified lineage (SAUL)) (Figure 1). Hence, the overall known diversity in sponges-from this and previous studies-increases to 32 different bacterial phyla and candidate phyla, which is similar to the reported number of 35 phyla found in other marine habitats such as the Arctic Ocean and the Western English Channel (Gilbert et al., 2009; Galand et al., 2009b). Given the sequencing depth of next-generation sequencing technologies and the large number of different sponges used in this study, we may now be approaching the total bacterial diversity at phylum level. However, it should be noted that detection of novel phyla also depends on the tag assignment methods and the taxonomy implemented in the reference database. This is particularly relevant for candidate phyla, which are often inadequately labeled in those databases (see below).

The most diverse phyla among those detected in this study are Proteobacteria with 942 different $97 \%$ OTUs distributed across all five classes (Alpha, Beta, Gamma, Delta and Epsilon), and Chloroflexi with 502 different 97\% OTUs (Figure 1a). This is consistent with data from sponge-derived 16S rRNA gene libraries where both of these phyla are often represented by many different phylotypes (Hentschel et al., 2002; Taylor et al., 2007; Lee et al., 2009). The third most diverse group in this study is the Poribacteria, a candidate phylum that was so far barely detected outside of sponges (but see Mohamed et al., 2010; Pham et al., 2008). Poribacteria are known to be abundant in and widespread among sponges (Fieseler et al., 2004; Lafi et al., 2009). A total of 437 different $97 \%$ OTUs in the whole data set and up to 79 different $97 \%$ OTUs in one host species shows that Poribacteria are also extremely diverse. Other detected phyla that are well known from sponges include Acidobacteria, Actinobacteria, Cyanobacteria, Gemmatimonadetes and Bacteroidetes, each represented by 42-169 different $97 \%$ OTUs. Also noteworthy is the phylum Fusobacteria as it represents the only bacterial phylum that was found exclusively in one species, the New Zealand sponge Stelletta maori. Members of Fusobacteria were recently found to be associated with diseased corals (Thurber et al., 2009) and it is conceivable that one or all of the sampled $S$. maori individuals was unhealthy although visually this did not appear to be the case. Alternatively, members of Fusobacteria may be specifically associated with $S$. maori alone.

In addition to Poribacteria, eight more candidate phyla were detected in the sponge data set (Figure 1b). The term 'candidate division' was previously created for phyla that lack cultivated members and are typically known only from $16 \mathrm{~S}$ rRNA gene sequence data (Hugenholtz et al., 1998). Before our tag sequence assignment, the taxonomic annotation of various candidate phyla in the reference SILVA database was manually corrected and sequence similarities to tag sequences were in many cases above $90 \%$. Where sequence similarity was lower, for example, $80 \%$ in the case of the OP3-related 97\% OTU, the taxonomic status was further verified by additional sequence analysis (for example, further BLAST searches). Thus, the detection of these phyla is not due to ambiguous taxonomic assignment of tag sequences, which sometimes can be problematic because of their short length (Webster et al., 2010). Members of all of these eight candidate phyla were found before in other marine habitats such as seawater, marine sediments or hydrothermal vents (Stott et al., 2008; Harrison et al., 2009; Portillo and Gonzalez 2009) but with the 


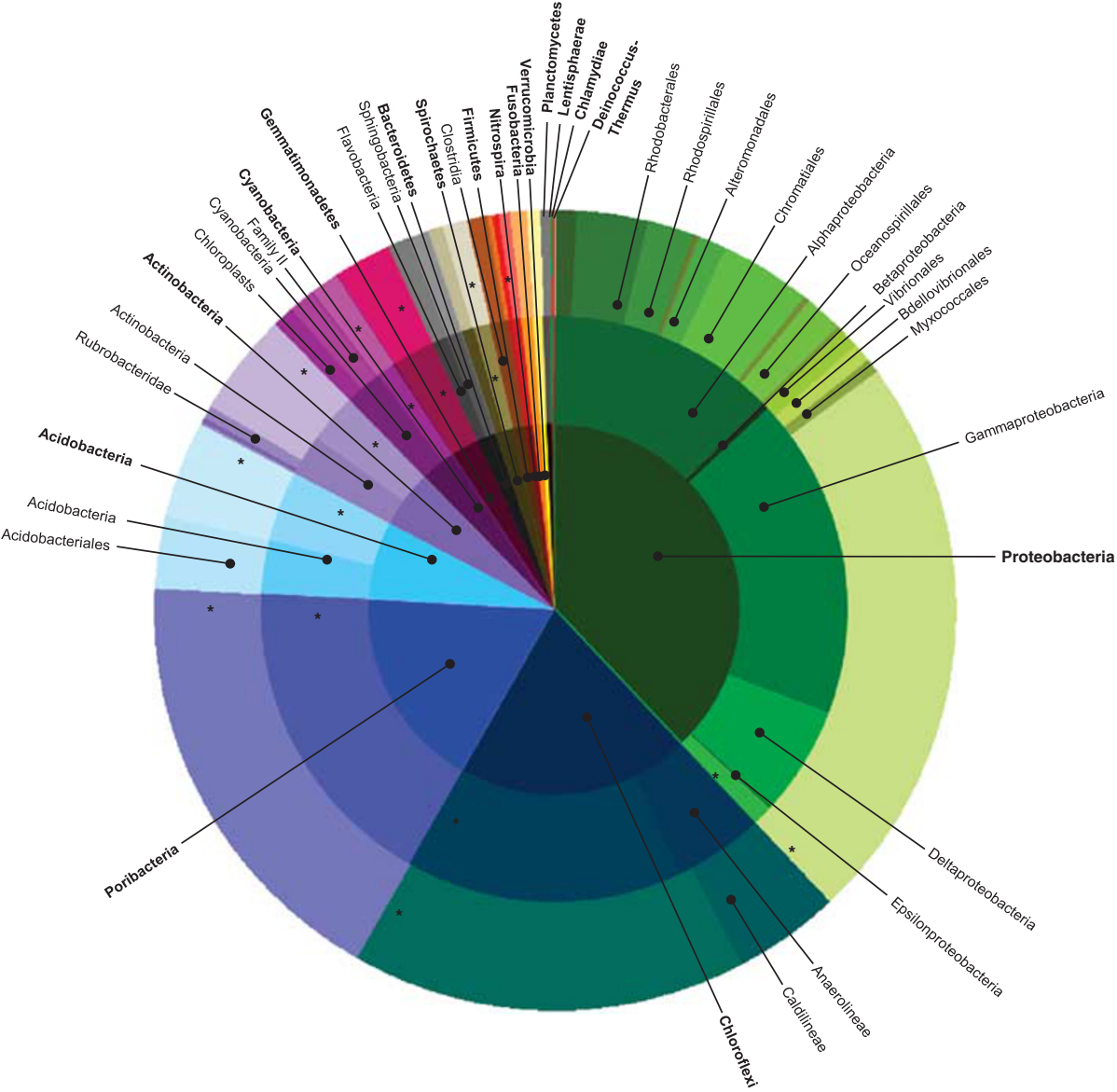

b No. of OTUs

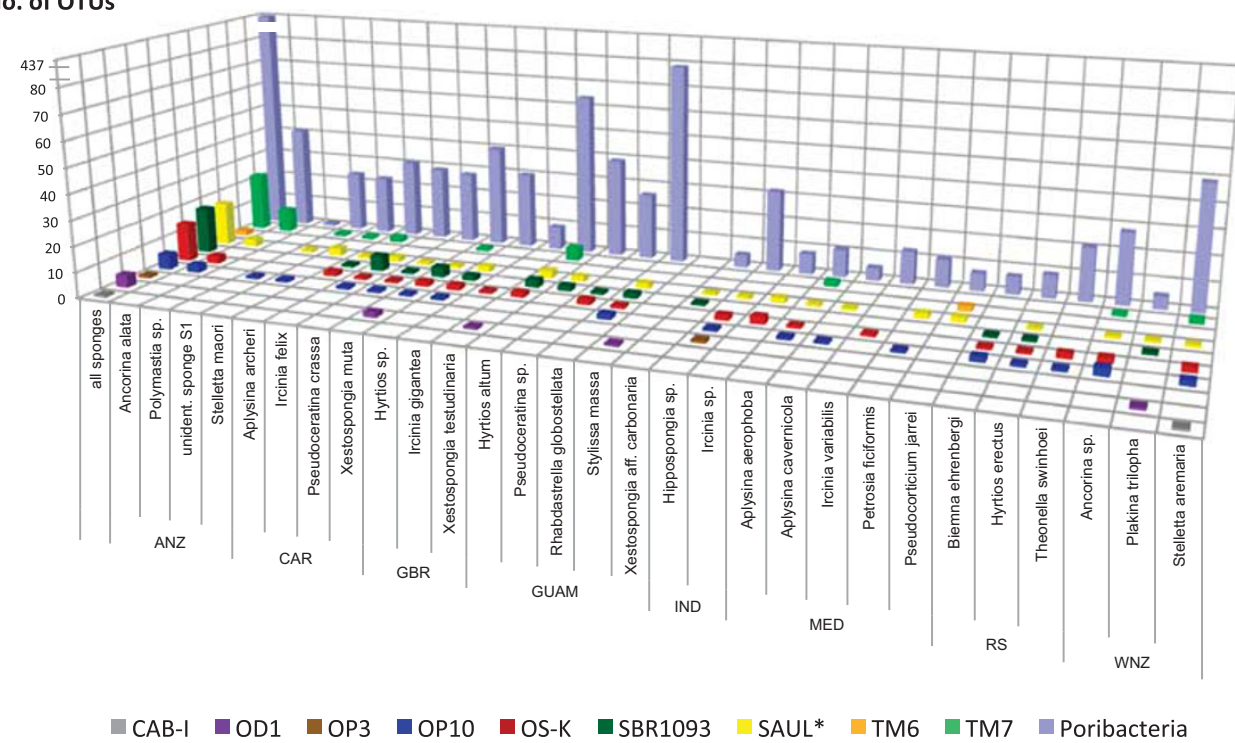

Figure 1 Bacterial richness in sponges. (a) Phylogenetic distribution of 97\% OTUs on phylum (inner circle), class (middle circle) and order level (outer circle). Only taxonomically described phyla and the candidate phylum Poribacteria are shown. Phylum names are given in bold. Selected class and order groups are labeled. *represents unclassified groups. (b) Taxonomic richness of 97\% OTUs that were assigned to candidate phyla, for all sponges and for each sponge species. ${ }^{*}$ indicates a sponge-associated unclassified lineage (SAUL). ANZ, Auckland, New Zealand; CAR, Caribbean Sea; GBR, Great Barrier Reef; GUAM, Guam, Pacific Ocean; IND, Indian Ocean; MED, Mediterranean Sea; RS, Red Sea; WNZ, Wellington, New Zealand. 
exception of TM6 and TM7, were not previously known to inhabit sponges. Among the additionally detected candidate phyla, TM7 was most diverse with 23 recorded 97\% OTUs and was previously found to be present and vertically transmitted in the sponge Xestospongia muta (Schmitt et al., 2008). The phyla OS-K and OP10 were most widely distributed (in 19 and 17 sponge species, respectively, from all eight sampling locations) whereas SBR1093 was most diverse within a single host species, with six 97\% OTUs found in Ircinia felix. However, most candidate phyla were represented by only one or two $97 \%$ OTUs per sponge species. It seems that these candidate phyla are generally not diverse but widespread among sponges. The SAUL lineage was found before in sponges (Taylor et al., 2007; Kamke et al., 2010) and, according to previous phylogenetic analyses, belongs to the Planctomycetes-VerrucomicrobiaChlamydiae (PVC) superphylum (Wagner and Horn 2006). However, it remains unclear whether the SAUL lineage falls within one of the phyla in this group or whether it represents a novel candidate phylum alongside Poribacteria and WS3 in the Planctomycetes-Verrucomicrobia-Chlamydiae superphylum.

Analysis of lower taxonomic levels revealed several interesting bacterial groups in the sponge data set (Figure 1a). For example, the genera Nitrosospira, Nitrospina and Nitrospira all represent nitrifying bacteria. Both ammonia-oxidizing and nitrite-oxidizing bacteria were found in sponges before using specific primers (Bayer et al., 2008; Hoffmann et al., 2009), however, our data suggest that only the genus Nitrospira (which contains nitrite oxidizers) is widely distributed in these hosts. Potential sulfate reducers were also detected, for example, $97 \%$ OTUs in the genus Desulfovibrio and the family Desulfobulbaceae, confirming previous data on sulfate reduction in other sponges (Hoffmann et al., 2005). However, with few exceptions (for example, nitrifying microbes), 16S rRNA gene data can generally not be used to make inferences about metabolic capabilities of microbes. For sulfate reducers, additional physiological experiments would be needed. Included among the detected bacterial groups of this study are also wellknown producers of bioactive substances. Examples are Streptosporangineae within the Actinobacteria and Rhodobacteraceae, Pseudoalteromonas and Sphingomonadaceae within the Proteobacteria, which highlights the potential of sponges as sources of novel natural products.

Are there bacterial sub-populations defined by host-dependency or geography?

To determine the distribution and biogeography of sponge symbionts and to test whether host- or geography-dependent sub-populations exist among the sponge symbionts, the 454 data were analyzed in relation to sponge phylogeny and sampling loca- tions. Figure 2 shows the similarity of microbial communities among the 32 sponge species of this study. With some exceptions, for example, the sponges Polymastia sp. and Cymbastela coralliophila that both have low microbial abundances (Kamke et al., 2010, J Vacelet, personal observation), the similarity is generally above $60 \%$ and often much higher (Figure 2). However, sponges within each one of the nine sponge orders represented in this study do not contain more similar microbial communities to each other than to species from the other orders (Figure 2). In addition, a clear correlation between microbial community similarity and host phylogeny was also not evident in a more detailed cluster analysis using three species of each of the genera Aplysina, Hyrtios and Ircinia, although some clustering according to sponge phylogeny was found at order level (Figure 3). Such a co-speciation pattern, where closely related sponges contain more similar microbial communities compared with distantly related sponges, would be expected if sponge symbionts were strictly transmitted via reproductive stages to the next generation. Vertical transmission of single lineages and of complex microbial communities has been shown for several sponges including some of the species investigated in this study (Usher et al., 2001; Oren et al., 2005; Enticknap et al., 2006; Schmitt et al., 2007; Sharp et al., 2007). However, it was previously proposed that vertical transmission is not the only mechanism of symbiont acquisition and that sponge symbionts may additionally be acquired from the seawater (Taylor et al., 2007; Schmitt et al., 2008; Webster et al., 2010). Such a combination of vertical and horizontal/environmental symbiont transmission would explain the lack of correlation between microbial community similarity and sponge phylogeny seen in this and previous studies.

Biogeographic distribution patterns of sponge symbionts were investigated by combining all tag sequences from each location and then defining and comparing 97\% OTUs. Microbial community similarities among different locations were generally high $(>75 \%$, Figure 4). Assuming that sponge symbionts occur outside of sponges (as environmental transmission would suggest) and considering the world's ocean currents, it is conceivable that sponges from some locations that are connected by ocean currents share more similar microbial communities than sponges from more isolated collection sites, as has been shown for marine microbes (Galand et al., 2009a, 2010). For example, while the Mediterranean Sea and the Red Sea each represent almost separate bodies of water, the three sampling sites in the South Pacific (Great Barrier Reef and Auckland and Wellington in New Zealand) are connected by the East Australian Current that moves water along the east coast of Australia and causes the mixture of the Tasman Sea between Australia and New Zealand. However, analysis of Bray-Curtis similarity values does not show such a 


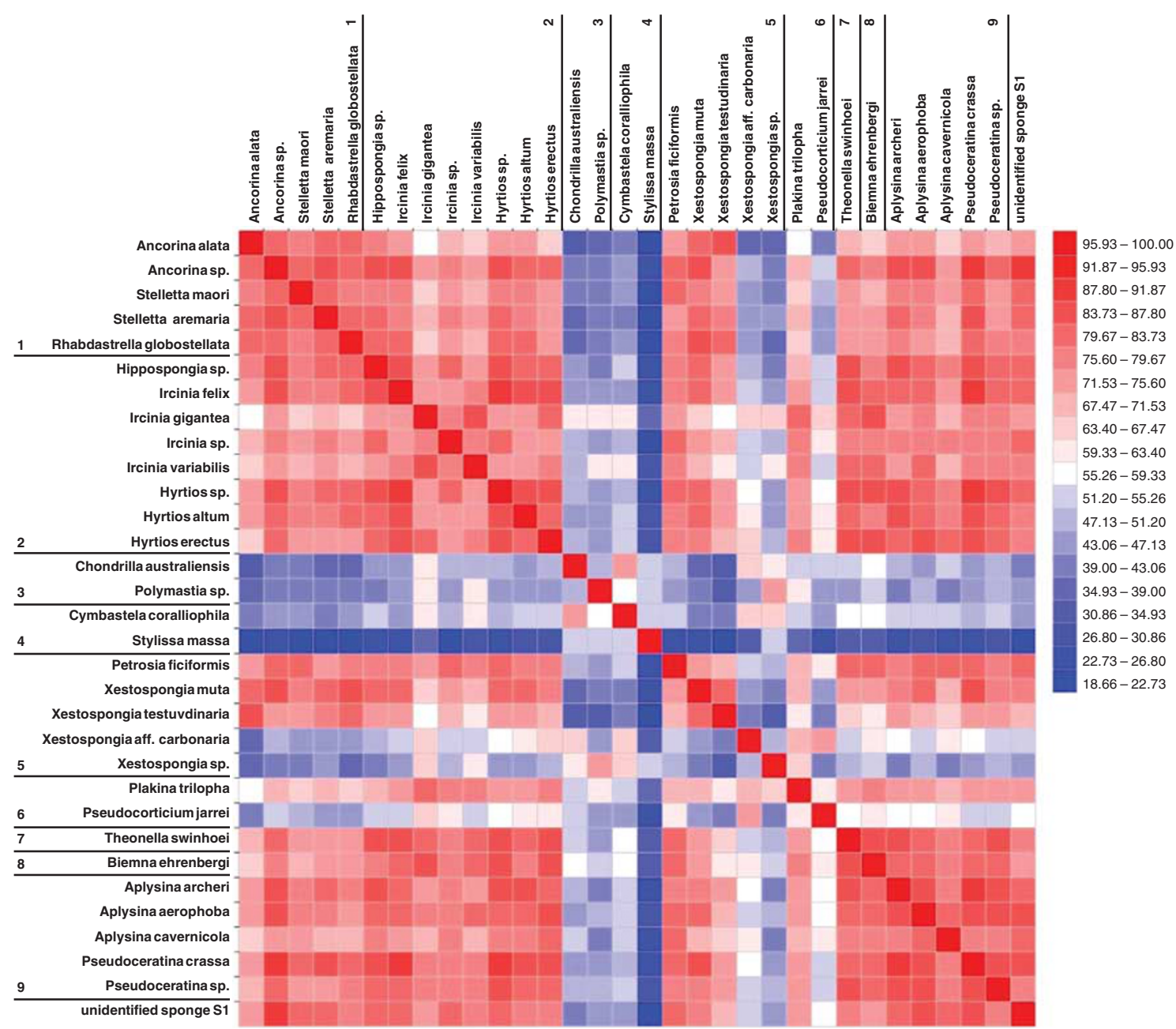

Figure 2 Microbial community similarity among 32 sponge species. Heat map displaying Bray-Curtis similarities based on abundances of assigned $97 \%$ OTUs at phylum level (75\% sequence similarity) is shown. Sponges are listed according to their taxonomy and orders are labeled as follows: 1, Astrophorida; 2, Dictyoceratida; 3, Hadromerida; 4, Halichondrida; 5, Haplosclerida; 6, Homosclerophorida; 7, Lithistida; 8, Poecilosclerida; 9, Verongida.

correlation between microbial community similarity and ocean currents. Instead, the Great Barrier Reef samples cluster with those from Guam (Northern Pacific Ocean) and the Caribbean Sea with a high similarity of $>90 \%$ (Figure 4). Interestingly, these three locations are the only tropical sites whereas all remaining locations are in the subtropics. The finding of such a tropical clade might indicate the existence of bacterial sub-populations among sponge symbionts defined by temperature or water salinity rather than ocean currents.

Core, variable and species-specific bacterial communities in marine sponges

The distribution of OTUs within the sponge samples was investigated by combining all tag sequences, defining $97 \%, 95 \%$ and $90 \%$ OTUs, and determining their presence in different sponges. A surprising negative exponential distribution pattern was observed. More than half of all OTUs were present in only a single sponge whereas only very few OTUs were present in many sponges (Figure 5). On the basis of this result, the microbiota in sponges was divided into the following groups: (1) core community (defined as presence of OTUs in at least $70 \%$ $(N=22)$ of the analyzed sponges); (2) variable community (defined as presence in $<70 \%$ of sponges but in at least two species); and (3) species-specific community (defined as presence in only a single sponge species).

All OTUs were also divided into Plus- and MinusOTUs depending on whether they were assignedduring the taxonomic assignment-to a previously sponge-derived sequence in the database (PlusOTU) or to a non-sponge-derived sequence (MinusOTU). This definition was used because a proper phylogenetic tree analysis and determination of sponge-specific clusters according to Hentschel et al. (2002) was not feasible with the short tag sequences. Nevertheless, the distinction into Plus- and Minus-OTUs allowed a comparison with previously published, sponge-derived sequences. Figure 6 shows the percentage of Plus-OTUs within 

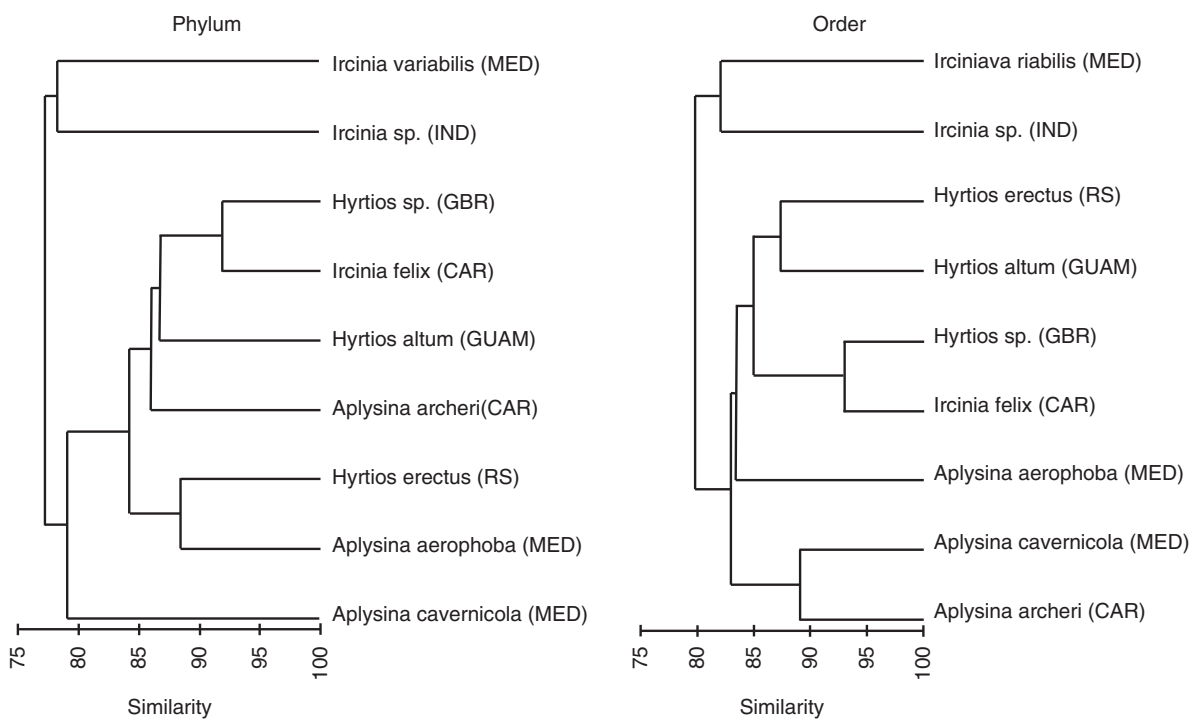

Figure 3 Microbial community similarity among Aplysina, Hyrtios and Ircinia sponges. Cluster analysis based on Bray-Curtis similarities of assigned $97 \%$ OTUs on phylum (75\% sequence similarity) and order (80\% sequence similarity) level is shown. CAR, Caribbean Sea; GBR, Great Barrier Reef; GUAM, Guam, Pacific Ocean; IND, Indian Ocean; MED, Mediterranean Sea; RS, Red Sea.

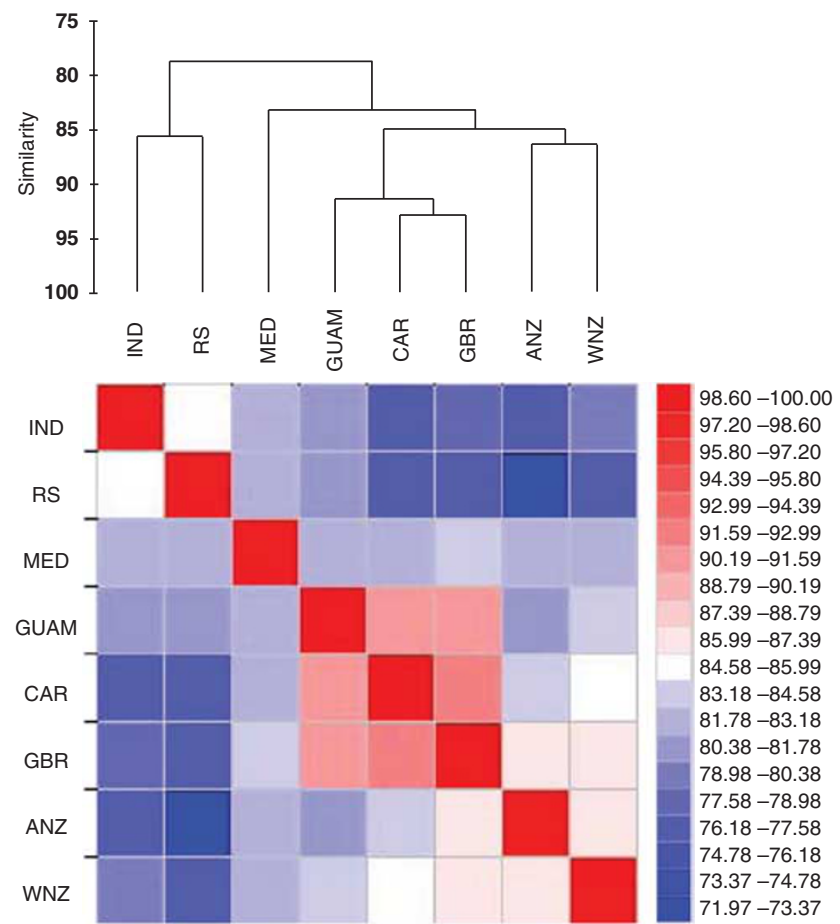

Figure 4 Microbial community similarity among eight sampling locations. Cluster analysis and heat map displaying Bray-Curtis similarities based on abundances of assigned $97 \%$ OTUs at phylum level (75\% sequence similarity) is shown. Ninety-seven percent OTUs were defined after combining tag sequences from each location. ANZ, Auckland, New Zealand; CAR, Caribbean Sea; GBR, Great Barrier Reef; GUAM, Guam, Pacific Ocean; IND, Indian Ocean; MED, Mediterranean Sea; RS, Red Sea; WNZ, Wellington, New Zealand.

each of the 32 sponges. An average of $64 \%$, and as much as $80 \%$ of all OTUs in a single sponge, were designated as Plus-OTUs showing a large overlap with previously published sponge-derived sequences. There are four notable exceptions with much fewer Plus-OTUs: Polymastia sp., Cymbastela coralliophila, Stylissa massa and Xestospongia sp. A possible explanation, at least for the first two mentioned sponges, is that they are low microbial abundance sponges that contain less diverse microbiota with a different compositional profile to high microbial abundance sponges (Hentschel et al., 2003; Kamke et al., 2010).

The core bacterial community consists of only three $97 \%$, eight $95 \%$ and 18 different $90 \%$ OTUs (Table 2). Not a single OTU was found in all 32 species. Therefore, the core bacterial community in sponges is rather small. All three 97\% core OTUs and many of the $95 \%$ and $90 \%$ core OTUs were affiliated with either Proteobacteria or Chloroflexi but none belonged to Poribacteria (Table 2). The fact that all core OTUs were detected in sponges from all eight sampling locations suggests a global distribution of the respective bacteria. Similarly, some free-living bacteria such as the SAR11 clade (Alphaproteobacteria), Alteromonas macleodii (Gammaproteobacteria) or Prochlorococcus/Synechococcus (Cyanobacteria) are believed to be ubiquitous marine bacteria with a global distribution (Morris et al., 2002; Bouman et al., 2006; IvarsMartinez et al., 2008a). Often, several ecotypes of these bacteria exist that are adapted to different environmental conditions (Rocap et al., 2003; Ahlgren and Rocap 2006; Ivars-Martinez et al., 2008b). It is conceivable that the core OTUs represent bacterial sponge ecotypes that are adapted to the niche sponge and are probably environmentally transmitted. This is also supported by the finding that most core OTUs represent Plus-OTUs (Table 2). Such a scenario would explain the presence of the same 97\% OTU (closely related bacteria) in geographically distinct sponges. 


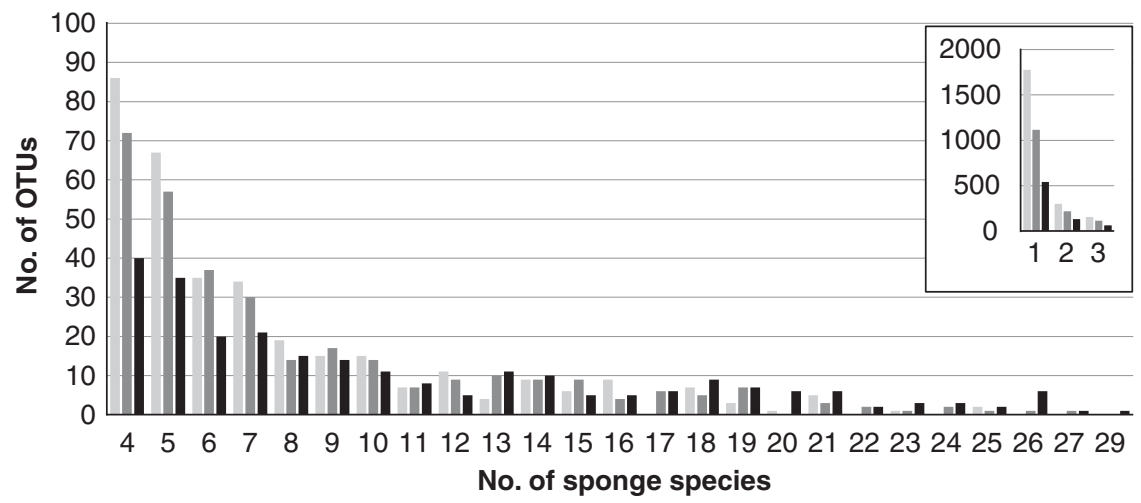

Figure 5 Distribution of 97 (light grey bar), 95 (dark grey bar) and 90\% (black bar) OTUs within 32 sponge species. Note that the inset (presence in 1, 2 or 3 sponge species) has a different bar.

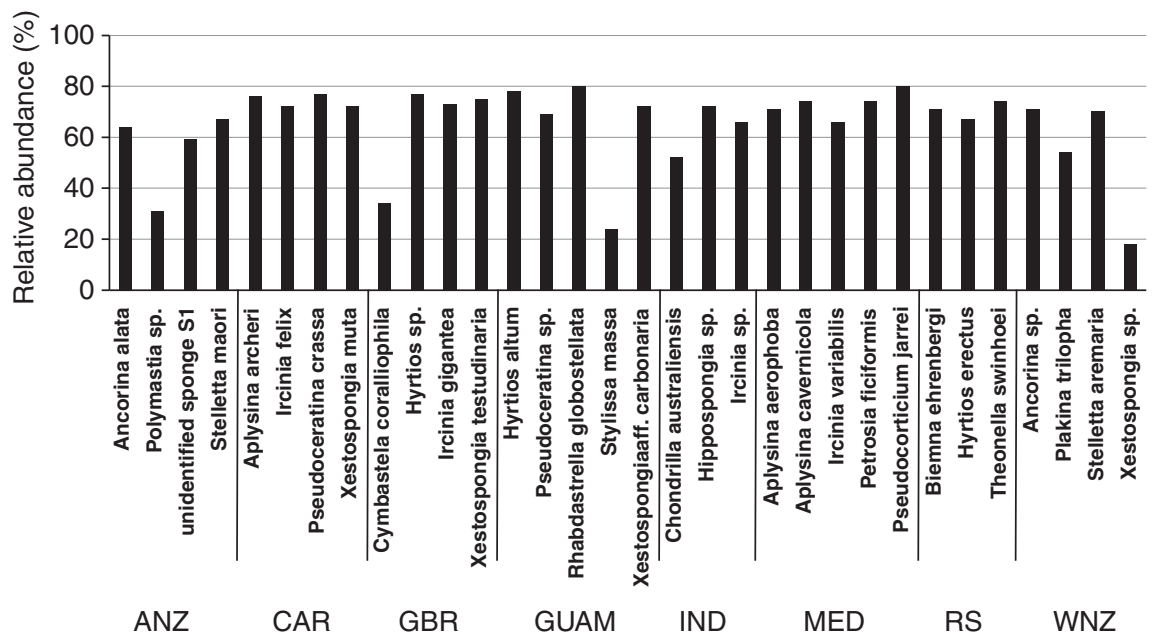

Figure 6 Relative abundance of Plus-OTUs within each sponge species. Distribution of 97\% OTUs that were assigned to a previously published sponge-derived 16S rRNA gene sequence (Plus-OTU). ANZ, Auckland, New Zealand; CAR, Caribbean Sea; GBR, Great Barrier Reef; GUAM, Guam, Pacific Ocean; IND, Indian Ocean; MED, Mediterranean Sea; RS, Red Sea; WNZ, Wellington, New Zealand.

In stark contrast to the core bacterial community, the species-specific community is very large and consists of $70 \%(N=1774)$ of $97 \%$ OTUs and twothirds $(N=1116)$ and half $(N=542)$ of $95 \%$ and $90 \%$ OTUs, respectively (Figure 7). The species-specific bacterial community contains members of all bacterial phyla and candidate phyla detected in this study with the exception of Deinococcus-Thermus (which is represented by a single OTU that was found in six species). Generally, the species-specific bacterial community consists of Plus- and MinusOTUs, however, the proportions of both OTU types within single phyla differ (Figure 7). Poribacteria are represented by only Plus-OTUs, which is in agreement with the fact that they were so far almost exclusively found within sponges (but see Mohamed et al., 2010; Pham et al., 2008). Chloroflexi, Acidobacteria and Gemmatimonadetes contain many more Plus- than Minus-OTUs whereas the opposite is true for e.g. Bacteroidetes and Planctomycetes. The host species-specific bacterial com- munity in sponges is probably mainly vertically transmitted. This would result in a separation of the symbionts within their hosts and would explain the observation that many $97 \%$ OTUs are only present in one sponge but are still most similar to other sponge-derived 16S rRNA gene sequences. Given that some of these bacteria show sequence divergences of $>10 \%$, such separation must have happened over a long time, pointing to an ancient association with their host sponges.

Figure 8 summarizes the different community types defined for the sponge microbiota and their proportions when applying different OTU definitions. A very similar distribution pattern of core, variable, and species-specific Plus- and MinusOTUs was observed when only one location (Mediterranean Sea) was investigated (Schmitt et al., 2011). We did not analyze our data quantitatively and therefore cannot make conclusions about relative abundances of certain bacteria in different hosts. If the core microbiota consists also of rare 
Table 2 Core bacterial community in sponges (List of 97\%, 95\% and 90\% OTUs present in 22 or more species. All OTUs were found at all eight locations)

\begin{tabular}{|c|c|c|c|c|}
\hline Tag ID & $\mathrm{N}_{\text {species }}$ & Score ${ }^{\mathrm{a}}$ & Taxonomic affiliation & Plus-OTU \\
\hline \multicolumn{5}{|l|}{$97 \%$ OTUs } \\
\hline INDIRC | F7F67TR11G0FCT | & 25 & 0.963 & Proteobacteria (alpha) & NA \\
\hline CARAPL I F7F67TR15I524M | & 25 & 0.992 & Chloroflexi & Yes \\
\hline GBRXES IF3FI3IU02HOUXZ | & 23 & 0.985 & Chloroflexi & Yes \\
\hline \multicolumn{5}{|l|}{$95 \%$ OTUs } \\
\hline AUKSTE |F7F67TR01ALMDZ | & 27 & 0.985 & Proteobacteria (alpha) & Yes \\
\hline INDIRC | F7F67TR11G0FCT | & 26 & 0.992 & Proteobacteria (alpha) & NA \\
\hline MEDAERO | F7F67TR12HEAY1 | & 25 & 0.970 & Chloroflexi & Yes \\
\hline RSTHEO |F7F67TR04CBKLL | & 24 & 0.992 & Actinobacteria & Yes \\
\hline INDIRC | F7F67TR11GR1PV| & 24 & 1 & Proteobacteria (gamma) & Yes \\
\hline GBRXES I F3FI3IU02HOUXZ | & 23 & 0.985 & Chloroflexi & Yes \\
\hline INDIRC |F7F67TR11GXKZ2 | & 22 & 0.992 & Proteobacteria (alpha) & Yes \\
\hline GBRXES I F7F67TR03BTEAA | & 22 & 0.992 & Chloroflexi & Yes \\
\hline \multicolumn{5}{|l|}{$90 \%$ OTUs } \\
\hline INDIRC IF7F67TR11GYCL4 | & 29 & 0.993 & Nitrospira & Yes \\
\hline AUKSTE |F7F67TR01ALMDZ | & 27 & 0.985 & Proteobacteria (alpha) & Yes \\
\hline AUKANC | F3FI3IU02JCBCF | & 26 & 0.994 & Proteobacteria (gamma) & Yes \\
\hline AUKS1 | F7F67TR02A4WJ7 | & 26 & 0.992 & Proteobacteria (alpha) & Yes \\
\hline AUKANCIF7F67TR01ARLEH | & 26 & 0.992 & Proteobacteria (alpha) & No \\
\hline RSTHEO | F7F67TR04CBKLL | & 26 & 0.992 & Actinobacteria & Yes \\
\hline AUKSTE |F7F67TR01APO5O| & 26 & 0.993 & Cyanobacteria & Yes \\
\hline INDHIP | F7F67TR12HE9V4 | & 26 & 0.993 & Chloroflexi & Yes \\
\hline MEDAERO IF7F67TR12HEAY1 I & 25 & 0.970 & Chloroflexi & Yes \\
\hline AUKANC | F3FI3IU02JPC91 | & 25 & 0.992 & Chloroflexi & Yes \\
\hline GBRXES | F3FI3IU02HOUXZ | & 24 & 0.985 & Chloroflexi & Yes \\
\hline GBRXES I F3FI3IU02GYNJB | & 24 & 0.977 & Chloroflexi & Yes \\
\hline CARXES IF7F67TR16JQN2I| & 24 & 0.992 & Chloroflexi & Yes \\
\hline CARIRC I F7F67TR15I91FO | & 23 & 0.987 & Acidobacteria & Yes \\
\hline GUAMPSEUDO |F7F67TR09FO9DI| & 23 & 0.927 & Firmicutes & No \\
\hline AUKANC I F7F67TR01AIB3U | & 23 & 0.962 & Proteobacteria (gamma) & No \\
\hline INDIRC I F7F67TR11GXKZ2 | & 22 & 0.992 & Proteobacteria (alpha) & Yes \\
\hline MEDPET IF7F67TR08ERRYN I & 22 & 0.992 & Proteobacteria (alpha) & No \\
\hline
\end{tabular}

Abbreviations: NA, not assigned; OTU, operational taxonomic unit.

${ }^{\text {aS }}$ core indicates similarity to reference sequence used for taxonomic assignment.

${ }^{\mathrm{b}}$ As defined by having a previously sponge-derived $16 \mathrm{~S}$ rRNA gene sequence as most similar reference sequence.

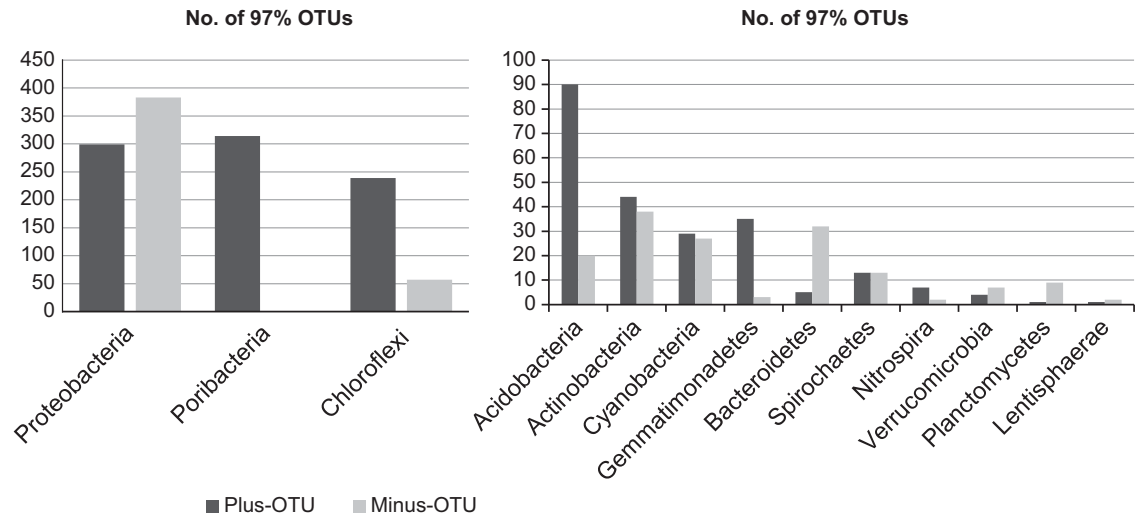

Figure 7 The species-specific bacterial community in sponges. Distribution of 97\% Plus- and Minus-OTUs among different bacterial phyla. Note that the species-specific community contains members of all phyla and candidate phyla detected in this study, with the exception of Deinococcus-Thermus, but only those phyla that contain Plus-OTUs are shown.

members then it is possible that the core is in fact larger than described here because very rare sequences might have been missed with our approach. However, it can safely be said that sponges do not share many abundant microbes. Interestingly, our findings are very similar to the results of the human gut microbiota that also consists of a small core of shared abundant bacterial species (Hamady and Knight 2009; Tschop et al., 2009; Turnbaugh et al., 2009). However, despite high variability at the species level, there is a core of shared gene families in the human gut microbiome, which suggests that different combinations of species can fulfill the same functional roles 


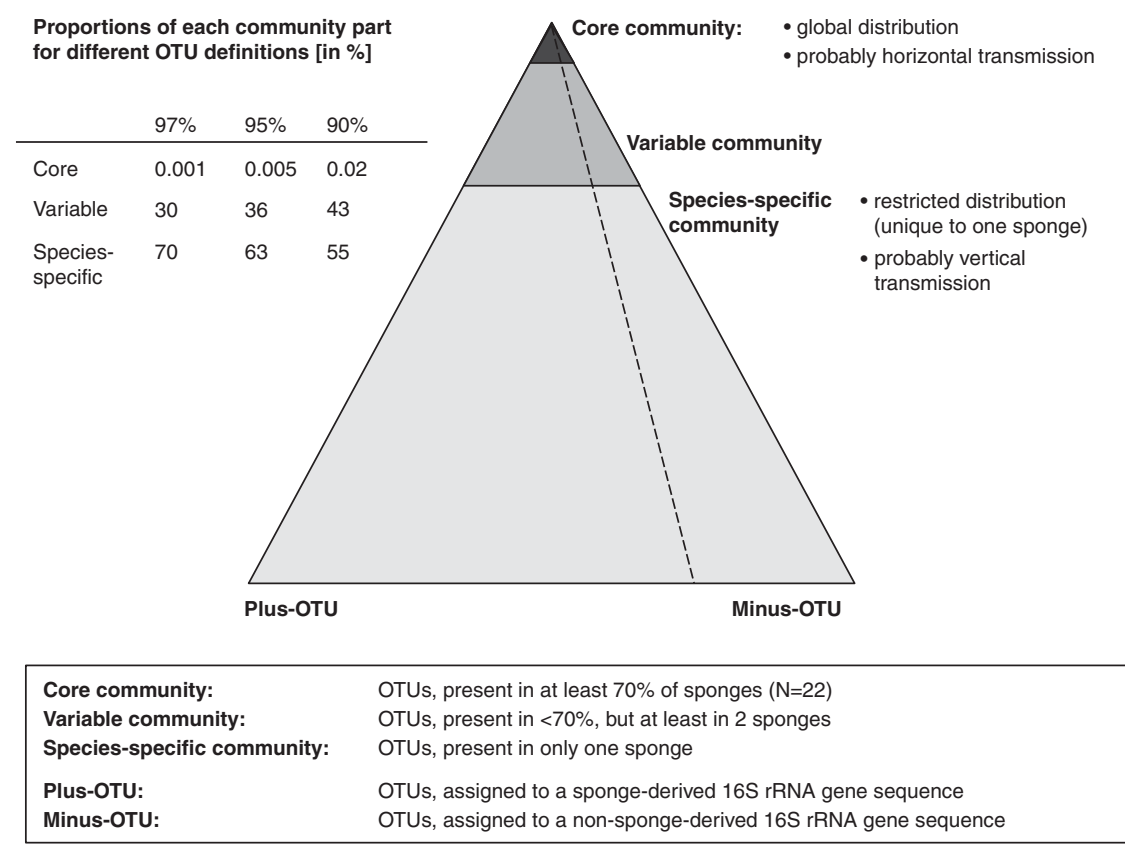

Figure 8 Schematic representation of the sponge microbiota that was divided into core, variable and species-specific bacterial communities.

(Turnbaugh et al., 2009). It is tempting to speculate that, similar to the human gut microbiota, the microbiota in different sponges vary extensively in the composition of bacterial species but are similar in their functional profiles. A recent metagenomic study provided one of the first detailed functional profiles of the microbial community within a sponge (Thomas et al., 2010b). Similar studies in the future using different sponges will enable testing of this hypothesis.

\section{Conclusions}

Analysis of $16 \mathrm{~S}$ rRNA gene amplicon pyrosequencing data from 32 sponges around the world's oceans allowed novel insights into the complex composition of sponge-microbe associations. Comparison of bacterial communities at broader taxonomic levels (phylum, order) revealed a high overall similarity but no correlation with sponge phylogeny. However, a tropical, biogeographical clade was identified. Comparison of bacterial communities using different OTU definitions revealed a minimal core and a large host species-specific bacterial community. Finally, comparison of bacterial communities to previously published data from sponges using Plus- and MinusOTU definitions indicated an overall large overlap with other, previously investigated sponge microbiota. On the basis of these results, we propose the following hypothesis: different sponges contain bacterial communities consisting of mainly different bacterial species (species-specific community) and share very few bacterial species (core community). However, the bacterial species in different sponges are still more closely related to each other than to, for example, seawater bacteria (indicated by Plus-OTUs and sponge-specific clusters), consistent with previous studies suggesting at least partially overlapping communities among different sponges. Sponges therefore contain a uniform, sponge-specific bacterial community although each sponge species contains different bacterial species.

\section{Acknowledgements}

We thank D Sutton (University of Western Australia, Perth, Australia), O Gomez (Western Australian Museum, Perth, Australia) and J Berman (Victoria University, Wellington, New Zealand) for help with sponge sampling. Research was generously supported by two German Research Foundation (DFG) Grants (Schm2559/1-1, 2-1) and a stipend in the program 'Chancengleichheit' of the University of Wuerzburg to SS, NIH MBRS SCORE Grant S06-GM-44796 to PJS and UoA Faculty Research Development Fund Grants (3609286 and 3622989) to MWT.

\section{References}

Ahlgren NA, Rocap G. (2006). Culture isolation and culture-independent clone libraries reveal new marine Synechococcus ecotypes with distinctive light and N physiologies. Appl Environ Microbiol 72: 7193-7204.

Altschul SF, Gish W, Miller W, Myers EW, Lipman DJ. (1990). Basic local alignment search Tool. J Mol Biol 215: 403-410.

Andersson AF, Riemann L, Bertilsson S. (2010). Pyrosequencing reveals contrasting seasonal dynamics of taxa within Baltic Sea bacterioplankton communities. ISME J 4: 171-181.

Bayer K, Schmitt S, Hentschel U. (2008). Physiology, phylogeny and in situ evidence for bacterial and 
archaeal nitrifiers in the marine sponge Aplysina aerophoba. Environ Microbiol 10: 2942-2955.

Bouman HA, Ulloa O, Scanlan DJ, Zwirglmaier K, Li WKW, Platt T et al. (2006). Oceanographic basis of the global surface distribution of Prochlorococcus ecotypes. Science 312: 918-921.

Chou HH, Holmes MH. (2001). DNA sequence quality trimming and vector removal. Bioinformatics 17: 1093-1104.

Costello EK, Lauber CL, Hamady M, Fierer N, Gordon JI, Knight R. (2009). Bacterial community variation in human body habitats across space and time. Science 326: 1694-1697.

Enticknap JJ, Kelly M, Peraud O, Hill RT. (2006). Characterization of a culturable alphaproteobacterial symbiont common to many marine sponges and evidence for vertical transmission via sponge larvae. Appl Environ Microbiol 72: 3724-3732.

Fieseler L, Horn M, Wagner M, Hentschel U. (2004). Discovery of the novel candidate phylum 'Poribacteria' in marine sponges. Appl Environ Microbiol 70: 3724-3732.

Galand PE, Casamayor EO, Kirchman DL, Lovejoy C. (2009a). Ecology of the rare microbial biosphere of the Arctic Ocean. Proc Natl Acad Sci USA 106: 22427-22432.

Galand PE, Casamayor EO, Kirchman DL, Potvin M, Lovejoy C. (2009b). Unique archaeal assemblages in the Arctic Ocean unveiled by massively parallel tag sequencing. ISME J 3: 860-869.

Galand PE, Potvin M, Casamayor EO, Lovejoy C. (2010). Hydrography shapes bacterial biogeography of the deep Arctic Ocean. ISME J 4: 564-576.

Gilbert JA, Field D, Swift P, Newbold L, Oliver A, Smyth T et al. (2009). The seasonal structure of microbial communities in the Western English Channel. Environ Microbiol 11: 3132-3139.

Hamady M, Knight R. (2009). Microbial community profiling for human microbiome projects: tools, techniques, and challenges. Genome Res 19: 1141-1152.

Harrison BK, Zhang H, Berelson W, Orphan VJ. (2009). Variations in archaeal and bacterial diversity associated with the sulfate-methane transition zone in continental margin sediments (Santa Barbara Basin, California). Appl Environ Microbiol 75: 1487-1499.

Hentschel U, Hopke J, Horn M, Friedrich AB, Wagner M, Hacker J et al. (2002). Molecular evidence for a uniform microbial community in sponges from different oceans. Appl Environ Microbiol 68: 4431-4440.

Hentschel U, Usher KM, Taylor MW. (2006). Marine sponges as microbial fermenters. FEMS Microbiol Ecol 55: $167-177$.

Hentschel U, Fieseler L, Wehrl M, Gernert C S, teinert M, Hacker J et al. (2003). Microbial diversity of marine sponges. In: Mueller W (ed), Marine Molecular Biotechnology. Springer: Berlin, pp 59-88.

Hochmuth T, Niederkrüger $H$, Gernert C, Siegl A, Taudien S, Platzer M et al. (2010). Linking chemical and microbial diversity in marine sponges: possible role for Poribacteria as producers of methyl-branched fatty acids. Chembiochem 11: 2572-2578.

Hoffmann F, Larsen O, Thiel V, Rapp HT, Pape T, Michaelis W et al. (2005). An anaerobic world in sponges. Geomicrobiol J 22: 1-10.

Hoffmann F, Rapp HT, Reitner J. (2006). Monitoring microbial community composition by fluorescence in situ hybridization during cultivation of the marine cold-water sponge Geodia barretti. Mar Biotechnol 8: 373-379.

Hoffmann F, Radax R, Woebken D, Holtappels M, Lavik G, Rapp HT et al. (2009). Complex nitrogen cycling in the sponge Geodia barretti. Environ Microbiol 11: 2228-2243.

Hollister EB, Engledow AS, Hammett AJM, Provin TL, Wilkinson HH, Gentry TJ. (2010). Shifts in microbial community structure along an ecological gradient of hypersaline soils and sediments. ISME J 4: 829-838.

Huber JA, Mark Welch D, Morrison HG, Huse SM, Neal PR, Butterfield DA et al. (2007). Microbial population structures in the deep marine biosphere. Science 318: 97-100.

Hugenholtz P, Pitulle C, Hershberger KL, Pace NR. (1998). Novel division level bacterial diversity in a Yellowstone hot spring. J Bacteriol 180: 366-376.

Ivars-Martinez E, D'Auria G, Rodriguez-Valera F, SanchezPorro C, Ventosa A, Joint I et al. (2008a). Biogeography of the ubiquitous marine bacterium Alteromonas macleodii determined by multilocus sequence analysis. Mol Ecol 17: 4092-4106.

Ivars-Martinez E, Martin-Cuadrado AB, D'Auria G, Mira A, Ferriera S, Johnson J et al. (2008b). Comparative genomics of two ecotypes of the marine planktonic copiotroph Alteromonas macleodii suggests alternative lifestyles associated with different kinds of particulate organic matter. ISME J 2: 1194-1212.

Joachimiak MP, Weisman JL, May BCH. (2006). JColorGrid: software for the visualization of biological measurement. BMC Bioinform 7: 225-229.

Kamke J, Taylor MW, Schmitt S. (2010). Activity profiles for marine sponge-associated bacteria obtained by $16 \mathrm{~S}$ rRNA vs $16 \mathrm{~S}$ rRNA gene comparisons. ISME J 4: 498-508.

Kennedy J, Marchesi JR, Dobson ADW. (2007). Metagenomic approaches to exploit the biotechnological potential of the microbial consortia of marine sponges. Appl Microbiol Biotechnol 75: 11-20.

Kunin V, Engelbrektson A, Ochman H, Hugenholtz P. (2010). Wrinkles in the rare biosphere: pyrosequencing errors can lead to artificial inflation of diversity estimates. Environ Microbiol 12: 118-123.

Lafi FF, Fuerst JA, Fieseler L, Engels C, Goh WWL, Hentschel U. (2009). Widespread distribution of Poribacteria in Demospongiae. Appl Environ Microbiol 75: 5695-5699.

Lee OO, Chui PY, Wong YH, Pawlik JR, Qian PY. (2009). Evidence for vertical transmission of bacterial symbionts from adult to embryo in the Caribbean sponge Svenzea zeai. Appl Environ Microbiol 75: 6147-6156.

Mohamed NM, Saito K, Tal Y, Hill RT. (2010). Diversity of aerobic and anaerobic ammonia-oxidizing bacteria in marine sponges. ISME J 4: 38-48.

Morris RM, Rappe MS, Connon SA, Vergin KL, Siebold WA, Carlson CA et al. (2002). SAR11 clade dominates ocean surface bacterioplankton communities. Nature 420: 806-810.

Oren M, Steindler L, Ilan M. (2005). Transmission, plasticity and the molecular identification of cyanobacterial symbionts in the Red Sea sponge Diacarnus erythraenus. Mar Biol 148: 35-41.

Pham VD, Konstantinidis KT, Palden T, DeLong EF (2008). Phylogenetic analyses of ribosomal DNAcontaining bacterioplankton genome fragments from 
a $4000 \mathrm{~m}$ vertical profile in the North Pacific Subtropical Gyre. Environ Microbiol 10: 2313-2330.

Portillo MC, Gonzalez JM. (2009). Members of the Candidate Division OP10 are spread in a variety of environments. World J Microbiol Biotechnol 25: 347-353.

Reeder J, Knight R. (2009). The 'rare biosphere': a reality check. Nat Methods 6: 636-637.

Reiswig HM. (1981). Partial carbon and energy budgets of the bacteriosponge Verongia fistularis (Porifera: Demospongiae) in Barbados West-Indies. Mar Ecol 2: 273-294.

Rocap G, Larimer FW, Lamerdin J, Malfatti S, Chain P, Ahlgren NA et al. (2003). Genome divergence in two Prochlorococcus ecotypes reflects oceanic niche differentiation. Nature 424: 1042-1047.

Schloss PD, Westcott SL, Ryabin T, Hall JR, Hartmann M, Hollister EB et al. (2009). Introducing mothur: opensource, platform-independent, community-supported software for describing and comparing microbial communities. Appl Environ Microbiol 75: 7537-7541.

Schmitt S, Weisz JB, Lindquist N, Hentschel U. (2007). Vertical transmission of a phylogenetically complex microbial consortium in the viviparous sponge Ircinia felix. Appl Environ Microbiol 73: 2067-2078.

Schmitt S, Angermeier $H$, Schiller R, Lindquist N, Hentschel U. (2008). Molecular microbial diversity survey of sponge reproductive stages and mechanistic insights into vertical transmission of microbial symbionts. Appl Environ Microbiol 74: 7694-7708.

Schmitt S, Hentschel U, Taylor MW. (2011). Deep sequencing reveals diversity and community structure of complex microbiota in five Mediterranean sponges. Hydrobiologia; e-pub ahead of print 7 July 2011; DOI: 10.1007/s10750-011-0799-9.

Sharp KH, Eam B, Faulkner DJ, Haygood MG. (2007). Vertical transmission of diverse microbes in the tropical sponge Corticium sp. Appl Environ Microbiol 73: $622-629$.

Siegl A, Hentschel U. (2010). PKS and NRPS gene clusters from microbial symbiont cells of marine sponges by whole genome amplification. Environ Microbiol Rep 2: 507-513.

Siegl A, Kamke J, Hochmuth T, Piel J, Richter M, Liang C et al. (2011). Single-cell genomics reveals the lifestyle of Poribacteria, a candidate phylum symbiotically associated with marine sponges. ISME J 5: 61-70.

Sipkema D, Holmes B, Nichols SA, Blanch HW. (2009). Biological characterisation of Haliclona (?gellius) sp.: sponge and associated microorganisms. Microbial Ecol 58: 903-920.

Sogin ML, Morrison HG, Huber JA, Mark Welch D, Huse SM, Neal PR et al. (2006). Microbial diversity in the deep sea and the underexplored 'rare biosphere'. Proc Natl Acad Sci USA 103: 12115-12120.

Stott MB, Crowe MA, Mountain BW, Smirnova AV, Hou SB, Alam M et al. (2008). Isolation of novel bacteria, including a candidate division, from geothermal soils in New Zealand. Environ Microbiol 10: 2030-2041.

Taylor MW, Schupp PJ, Dahllof I, Kjelleberg S, Steinberg PD. (2004). Host specificity in marine sponge-associated bacteria, and potential implications for marine microbial diversity. Environ Microbiol 6: 121-130.
Taylor MW, Radax R, Steger D, Wagner M. (2007). Spongeassociated microorganisms: evolution, ecology, and biotechnological potential. Microbiol Mol Biol Rev 71: 295-347.

Teixeira L, Peixoto RS, Cury JC, Sul WJ, Pellizari VH, Tiedje J et al. (2010). Bacterial diversity in rhizosphere soil from Antarctic vascular plants of Admiralty Bay, maritime Antarctica. ISME J 4: 989-1001.

Thomas TRA, Kavlekar DP, LokaBharathi PA. (2010a). Marine drugs from sponge-microbe association-a review. Marine Drugs 8: 1417-1468.

Thomas T, Rusch D, DeMaere MZ, Yung PY, Lewis M, Halpern A et al. (2010b). Functional genomic signatures of sponge bacteria reveal unique and shared features of symbiosis. ISME J 4: 1557-1567.

Thurber RV, Willner-Hall D, Rodriguez-Mueller B, Desnues C, Edwards RA, Angly F et al. (2009). Metagenomic analysis of stressed coral holobionts. Environ Microbiol 11: 2148-2163.

Tschop MH, Hugenholtz P, Karp CL. (2009). Getting to the core of the gut microbiome. Nat Biotechnol 27: 344-346.

Turnbaugh PJ, Hamady M, Yatsunenko T, Cantarel BL, Duncan A, Ley RE et al. (2009). A core gut microbiome in obese and lean twins. Nature 457: U480-U487.

Usher KM, Kuo J, Fromont J, Sutton DC. (2001). Vertical transmission of cyanobacterial symbionts in the marine sponge Chondrilla australiensis (Demospongiae). Hydrobiologia 461: 15-23.

Vacelet J. (1975). Étude en microscopie électronique de l'association entre bactéries et spongiaires du genre Verongia (Dictyoceratida). J De Microscopie Et De Biologie Cellulaire 23: 271-288.

Vacelet J, Donadey C. (1977). Electron-microscope study of association between some sponges and bacteria. J Experiment Mar Biol Ecol 30: 301-314.

Wagner M, Horn M. (2006). The Planctomycetes, Verrucomicrobia, Chlamydiae and sister phyla comprise a superphylum with biotechnological and medical relevance. Curr Opin Biotechnol 17: 241-249.

Webster NS, Cobb RE, Negri AP. (2008). Temperature thresholds for bacterial symbiosis with a sponge. ISME J 2: 830-842.

Webster NS, Taylor MW, Behnam F, Luecker S, Rattei T, Whalan S et al. (2010). Deep sequencing reveals exceptional diversity and modes of transmission for bacterial sponge symbionts. Environ Microbiol 12: 2070-2082.

Weisz JB, Hentschel U, Lindquist N, Martens CS. (2007). Linking abundance and diversity of sponge-associated microbial communities to metabolic differences in host sponges. Mar Biol 152: 475-483.

Wilkinson CR. (1979). Nutrient translocation from symbiotic cyanobacteria to coral reef sponges. In: Levi C, BouryEsnault N (eds), Biologie Des Spongiaires. Colloques International du Centre National de la Recherche Scientifique: Paris, France, pp 373-380.

Wilkinson CR, Nowak M, Austin B, Colwell RR. (1981). Specificity of bacterial symbionts in Mediterranean and Great Barrier-Reef sponges. Microbial Ecol 7: 13-21.

Supplementary Information accompanies the paper on The ISME Journal website (http://www.nature.com/ismej) 